\title{
Discovering Brugada syndrome during preoperative evaluation
}

\author{
Pattara Rattanawong • Tachapong Ngarmukos • \\ Treechada Wisaratapong
}

Received: 3 August 2014 / Accepted: 8 October 2014/Published online: 28 October 2014

(C) Japanese Society of Anesthesiologists 2014

\section{Keywords Brugada syndrome $\cdot$ Preoperative}

To the Editor:

A preoperative ECG of a febrile $\left(38.0^{\circ} \mathrm{C}\right) 56$-year-old Thai man diagnosed with acute appendicitis revealed type1 Brugada pattern (BrP) (Fig. 1a). His ECG was repeated at 15 and $30 \mathrm{~min}$, which showed type-2 BrP (Fig. 1b). The patient denied clinical manifestations or family history of Brugada syndrome (BrS). He was diagnosed with asymptomatic BrS.

Many asymptomatic BrS unmasked by fever have been reported. Moreover, fever has also triggered ventricular arrhythmias [1]. Electrophysiological study or drug challenge test should be done to stratify the risk of arrhythmias in asymptomatic $\mathrm{BrS}$ [2]. However, it is not suitable to perform such a test before emergency operation. Therefore,

Electronic supplementary material The online version of this article (doi:10.1007/s00540-014-1935-2) contains supplementary material, which is available to authorized users.

P. Rattanawong

Department of Internal Medicine, Satun Hospital, Satun,

Thailand

P. Rattanawong $(\square)$

4, Soi Srithammasok 4, Srithammasok Rd., Naimuang, Muang,

Nakhon Si Thammarat 80000, Thailand

e-mail: pattara.rattanawong@gmail.com

T. Ngarmukos

Division of Cardiology, Department of Internal Medicine,

Faculty of Medicine, Ramathibodi Hospital, Mahidol University,

Bangkok, Thailand

T. Wisaratapong

Division of Cardiology, Department of Internal Medicine, Faculty of Medicine, Songklanagarind Hospital, Prince of

Songkla University, Songkhla, Thailand to avoid exacerbation of ventricular arrhythmias, class IC/ IA antiarrhythmic drugs, epidural bupivacaine, acetylcholine, propranolol, propofol, pinacidil, and nicorandil should not be used [3].

In our case, by using general anesthesia, intravenous etomidate was used for induction and seroflurane was used for maintenance. Rocuronium was used as a muscle relaxant. ECG was monitored and external defibrillator was installed for the entire operation. The patient uneventfully went to an appendectomy. His ECG was normal during non-febrile state (Fig. 1c).

\section{Conclusions}

In conclusion, we suggest to empirically manage a patient as a high arrhythmia risk to prevent undesired life-threatening events in asymptomatic BrS diagnosed in emergency preoperative evaluation.

\section{Conflict of interest None.}

\section{References}

1. Adler A, Topaz G, Heller K, Zeltser D, Ohayon T, Rozovski U, Halkin A, Rosso R, Ben-Shachar S, Antzelevitch C, Viskin S. Fever-induced Brugada pattern: how common is it and what does it mean? Heart Rhythm. 2013;10:1375-82.

2. Stephenson EA, Berul CI. Electrophysiological interventions for inherited arrhythmia syndromes. Circulation. 2007;116:1062-80.

3. Inamura M, Okamoto H, Kuroiwa M, Hoka S. General anesthesia for patients with Brugada syndrome. A report of six cases. Can J Anaesth. 2005;52:409-12. 